Clinical Study

\title{
Bone Texture Fractal Dimension Analysis of Ultrasound-Treated Bone around Implant Site: A Double-Blind Clinical Trial
}

\author{
Elaf Akram Abdulhameed $\left(\mathrm{D},{ }^{1}\right.$ Natheer Hashim Al-Rawi $\left(\mathbb{D},{ }^{1}\right.$ Asmaa Tahseen Uthman, ${ }^{2}$ \\ and Ab Rani Samsudin $\mathbb{( D}^{1}$ \\ ${ }^{1}$ College of Dental Medicine, University of Sharjah, Sharjah, UAE \\ ${ }^{2}$ College of Dental Medicine, Gulf Medical University, Ajman, UAE
}

Correspondence should be addressed to Elaf Akram Abdulhameed; elaf.alzubaidi@gmail.com

Received 20 January 2018; Revised 17 February 2018; Accepted 19 March 2018; Published 15 April 2018

Academic Editor: Saso Ivanovski

Copyright (c) 2018 Elaf Akram Abdulhameed et al. This is an open access article distributed under the Creative Commons Attribution License, which permits unrestricted use, distribution, and reproduction in any medium, provided the original work is properly cited.

\begin{abstract}
Objectives. To evaluate the efficacy of bone texture fractal dimension (FD) analysis method in predicting implant stability from intraoral periapical radiographs using two implant protocols. Materials and Methods. A double-blind clinical trial was conducted on 22 subjects who needed dental implants. The participants were randomized into two groups, the control group with standard implant protocol treatment and the intervention group with added low-intensity power ultrasound treatment (LIPUS) besides the standard implant protocol. The FD values of bone density were carried out on the mesial and distal sides of the implant on digital intraoral radiographs using the box-counting method. Both resonance frequency (RF) and fractal dimension (FD) were assessed in three time intervals: after surgery and before and after loading. Results. FD on both the mesial and distal sides serve as very good-to-excellent tests with high validity (ROC area exceeding 0.8 ) in predicting high implant stability (ISQ $\geq 70$ ). The mesial side measurements were consistently better than the distal side among the intervention groups. The optimum cutoff value for the FDmesial side that predicts a highly stable implant (ISQ $\geq 70$ ) is $\geq 1.505$. At this optimum cutoff value, the mesial side FD is associated with a perfect sensitivity (100\%) and fairly high specificity (86.5\%). Conclusion. The FD analysis could be recommended as an adjunctive quantitative method in prediction of the implant stability with very high sensitivity and specificity. This trial is registered with ISRCTN72648040.
\end{abstract}

\section{Introduction}

Sufficient bone quality is a prerequisite for a successful dental implant. Proper assessment of the bone quality is a primary objective to determine the osseointegration status. Excessive marginal bone loss after implant or following prosthesis may be seen in the first year [1]. Continuous bone resorption affects function and aesthetic; therefore, there are several ways recommended to restore and regenerate the bone such as advocating bone-grafting procedures, usage of growth factors, low-level laser therapy, and therapeutic ultrasound. Low-intensity pulsed ultrasound (LIPUS) stimulation is a safe noninvasive treatment, and it can accelerate bone regeneration [2]. In dentistry, LIPUS has been found to promote periodontal bone defect healing [3], bone regeneration after oral surgery [4], and osseointegration of an endosseous dental implant [5].

Histological analysis was usually considered the goldstandard method to evaluate successful osseointegration. However, due to the invasiveness of this method and related ethical issues, various imaging modalities have been proposed like intraoral radiographs, panoramic imaging, computed tomography (CT), cone beam computed tomography (CBCT), and micro-CT [6]. Periapical radiographs are traditionally interpreted by measuring peri-implant marginal bone loss. This method has been found with limited diagnostic value for early detection of bone changes [7].

Bone texture analysis provides information about bone structures in a noninvasive manner $[8,9]$. Fractal dimension analysis is one of the noninvasive, well-suited methods to 
analyze the bone texture on a plain radiograph [10]. This method is used to quantify the trabecular bone pattern and bone marrow interface using the box-counting logarithm $[11,12]$. The fractal analysis is a statistical analysis of texture based on fractal geometry for describing complex structural patterns recognized and expressed as a ratio termed as the "fractal dimension" FD $[13,14]$. The FD method has been used to quantify trabecular bone structures under different conditions, like endodontic treatment [15], periodontitis $[16,17]$, and implant stability $[18,19]$. Jolley et al. [20] showed that the FD can reliably analyze the changes in the alveolar bone density by using the periapical radiographs.

There has been no report to determine the validity of intraoral periapical radiographs to predict the success rate of implant stability. Plethora of reports have tested the bone quality around the dental implants and compared it with the contralateral normal bone, but no study has been conducted to compare bone changes between two implant protocols $[18,19]$. The aim of the present study was to evaluate the efficacy of the fractal dimension (FD) method in predicting stability around the dental implants treated with and without LIPUS from an intraoral periapical radiograph.

\section{Materials and Methods}

This randomized controlled clinical trial (RCT) was conducted on 22 patients attended to the University Dental Hospital Sharjah (UDHS) for dental implant therapy of single missing maxillary, first or second premolars. The age range was between 20 and 40 years (mean $33.13 \pm 7.23$ years). Patients with smoking habit or patients with any systemic diseases that might affect bone metabolism, or patients with parafunctional habits, and patients with active periodontal diseases or bad oral hygiene were excluded from the study. After explaining the study procedure, informed consent was obtained from all participants. The study participants were allocated randomly and equally divided into two groups; the control group $(n=11)$ received the standard implant treatment, and the intervention group $(n=11)$ which received low-intensity pulsed ultrasound (LIPUS) therapy in addition to the standard implant procedure.

All patients underwent 2 stages of implant surgeries. Stage I implant surgery was performed with one SPI dental implant (Thommen Medical SPI Element MC Inicell) bone level type with a length of $9.5 \mathrm{~mm}$, and a diameter of $4 \mathrm{~mm}$ was positioned in the maxillary edentulous premolar area in each patient. A stage II implant surgery was carried out after 2 months of implant placement where the dental implant was uncovered and impression was taken for crown placement. All patients received screw-retained porcelain fused to metal crown. The intervention group patients $(n=11)$ were then subjected to LIPUS exposure two weeks following stage I implant surgery placement. The machine employed was Pulson ${ }^{\circledR 3} 30$ Ultrasound Therapy unit (Gymna, Bilzen, Belgium) (Figure 1). According to Kerr et al. [21], the intensity of ultrasound therapy was set at $30 \mathrm{~mW} / \mathrm{cm}^{2}$ with a frequency of $1.5 \mathrm{MHz}$ and temporal average power of $20 \mathrm{~mW}$. LIPUS was delivered intraorally on the buccal part of the implant site for a duration of 20 minutes twice a week started 2 weeks after dental implant placement and lasted for the subsequent 10 weeks.

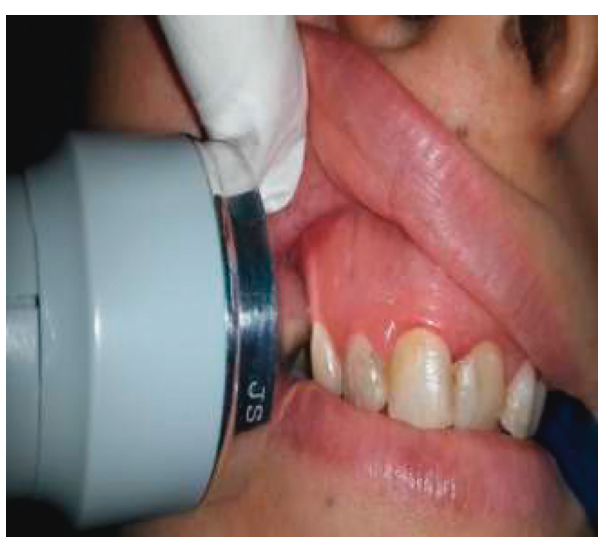

FIgURE 1: Ultrasound therapy delivered using probe on the buccal aspect of the implant site.

The RF measurements and the FD measurements of bone density were done immediately after surgical dental implant placement and after three and six months, respectively.

For the RF analysis technique, the implant stability is estimated using an Osstell Mentor (Integration Diagnostics, Goteborg, Sweden) and Smart Pegs as described by Isoda et al. [22]. The Smart Pegs were mounted on the implants and tightened with a screw. The RF value was measured in four aspects (mesial, distal, buccal, and lingual) for each implant. The RF values were represented by a quantitative unit called the implant stability quotient (ISQ) on a scale from 1 to 100. High stability means $>70$ ISQ, between 60 and 69 is medium stability, and $<60$ ISQ is considered as low stability. The results were expressed in ISQ and averaged for each implant.

The fractal dimension analysis (FD) was made on digital intraoral radiographic images that were taken immediately after the placement of the dental implant and at 3 months and 6 months postoperatively using Image $J$ software (https://imagej.nih.gov/ij/).

The region of interest $(\mathrm{ROI})$ was set to $100 \times 200$ pixels $(1.0 \mathrm{~mm}$ wide $\times 2.0 \mathrm{~mm}$ height $)$ at the first macrothread around the mesial and distal aspects of each implant.

The region of interest (ROI) was cropped and was transferred to Image J version 1.34 s by using the program menu. The saved images were processed using the White and Rudolph method [23]. ROI of duplicated image was blurred with a Gaussian filter (kernel size 35). The blurred image was then subtracted from the original image, and then, the resultant image was converted to binary by threshold at the gray value of 128 so that the segmented objects approximated the bony trabecular pattern. Finally, the image was skeletonized and was used for fractal analysis.

The fractal dimension of the skeletonized image was calculated using the box-counting function method mentioned by Demirbas et al. [24] The resulting numbers of the counted tiles (which refers to the trabecular bone) were plotted against the total number of the tiles in double logarithmic scale, and fractal dimension was calculated from the slope of the line fitted on the data points (Figure 2).

Data were expressed as mean and standard deviation (SD). Differences between groups were analyzed for significance using independent and paired $t$-test. A simple 


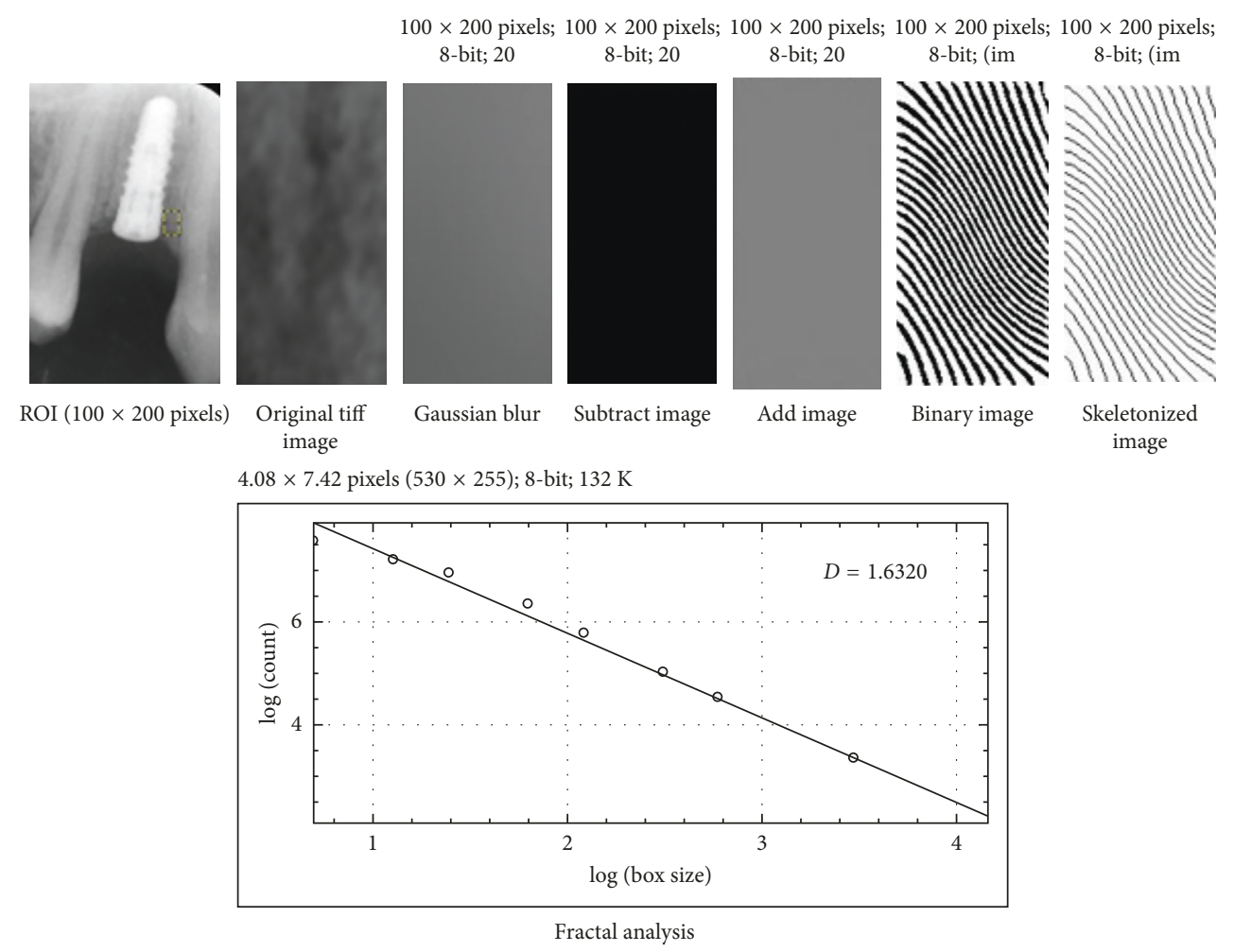

FIGURE 2: Image-processing procedure.

TABLE 1: Age and gender comparison between the intervention and control groups.

\begin{tabular}{|c|c|c|c|c|c|}
\hline & & & & & \\
\hline & & & & & $P$ \\
\hline & $N$ & $\%$ & $N$ & $\%$ & \\
\hline Age group (years) & & & & & 0.67 (NS) \\
\hline $21-30$ & 4 & 36.4 & 5 & 45.5 & \\
\hline $31-40$ & 7 & 63.6 & 6 & 54.5 & \\
\hline Total & 11 & 100.0 & 11 & 100.0 & \\
\hline Gender & & & & & 1 (NS) \\
\hline Female & 7 & 63.6 & 7 & 63.6 & \\
\hline Male & 4 & 36.4 & 4 & 36.4 & \\
\hline Total & 11 & 100.0 & 11 & 100.0 & \\
\hline
\end{tabular}

regression model was also used to predict the RF value based on measuring the FD. The statistical significance was defined as $P<0.05$ using SPSS statistical package (SPSS, Version 24, Chicago, IL, USA).

\section{Results}

3.1. Reliability and Randomization. FD analyses were done by one investigator (EA), all measurements were repeated by the same investigator after 2 weeks, the intraexaminer reliability test was evaluated, and intraclass correlation coefficient test was measured. The intraclass correlation coefficient was measured first, and it was 0.965 indicating very high internal consistency. There were no obvious or statistically significant differences in age and gender composition between the two comparison groups. This qualifies as an evidence for adequate randomization process (Table 1).
The mean and the standard deviation of RF and FD values for the intervention and control groups are seen in (Table 2).

All the paired measurements of RF and FD values on all study participants (irrespective of their study groups and follow-up time) and all the three time intervals were used in a simple regression model. The model was used to predict the RF value based on measuring the FD.

3.2. Resonance Frequency Analysis. The mean RF measured immediately after surgery showed no important or statistically significant differences between the control and intervention groups ( $55.3 \%$ and $53.2 \%$, resp.). This adds to the evidence for effective randomization process at the design stage (Table 3 and Figure 3).

The outcome of dental implant was assessed after three months and six months of surgery and compared to the immediate postoperative status. The mean change in $\mathrm{RF}$ 
TABLE 2: The means and standard deviations of RF and FD in the intervention and control groups.

\begin{tabular}{|c|c|c|c|c|c|c|c|c|c|}
\hline & \multicolumn{3}{|c|}{ RF Values (mean \pm SD) } & \multicolumn{3}{|c|}{ FD values $($ mean $\pm S D)$} & \multicolumn{3}{|c|}{ FD values $($ mean $\pm S D)$} \\
\hline & 0 month & 3 months & 6 months & 0 month & $\begin{array}{l}3 \text { months } \\
\text { Mesial side }\end{array}$ & 6 months & 0 month & $\begin{array}{l}3 \text { months } \\
\text { Distal side }\end{array}$ & 6 months \\
\hline Control group & $55.3 \pm 1.90$ & $59.45 \pm 4.50$ & $62.09 \pm 3.83$ & $1.18 \pm 0.19$ & $1.35 \pm 0.08$ & $1.44 \pm 0.06$ & $1.06 \pm 0.16$ & $1.24 \pm 0.07$ & $1.36 \pm 0.04$ \\
\hline Intervention group & $53.2 \pm 2.99$ & $65.91 \pm 6.30$ & $75.45 \pm 3.01$ & $1.42 \pm 0.10$ & $1.56 \pm 0.06$ & $1.68 \pm 0.09$ & $1.24 \pm 0.07$ & $1.35 \pm 0.06$ & $1.49 \pm 0.11$ \\
\hline
\end{tabular}

RF: resonance frequency; FD: fractal dimension.

TABLE 3: An intervention-control group comparison in mean change in the RF after three and six months of surgery compared to immediate postoperative measurements.

\begin{tabular}{|c|c|c|c|c|c|c|c|c|c|}
\hline & \multirow[b]{2}{*}{ At baseline } & \multicolumn{3}{|c|}{ Changes after } & \multicolumn{5}{|c|}{ Changes after } \\
\hline & & $\begin{array}{l}\text { After } 3 \\
\text { months }\end{array}$ & $\begin{array}{l}3 \text { months } \\
\text { compared to } \\
\text { immediate }\end{array}$ & Cohen's $d$ & $\begin{array}{c}P \text { (paired } \\
t \text {-test) }\end{array}$ & $\begin{array}{l}\text { After } 6 \\
\text { months }\end{array}$ & $\begin{array}{l}6 \text { months } \\
\text { compared to } \\
\text { immediate }\end{array}$ & Cohen's $d$ & 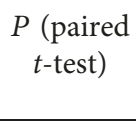 \\
\hline $\begin{array}{l}\text { Control } \\
\text { Range }\end{array}$ & (52 to 58 ) & (49 to 65 ) & $(-6$ to 11$)$ & & & (54 to 68 ) & $(-1$ to 13$)$ & & \\
\hline Mean & 55.3 & 59.5 & 4.2 & 1.21 & 0.009 & 62.1 & 6.8 & 2.25 & $<0.001$ \\
\hline SD & 1.9 & 4.5 & 4.3 & & & 3.8 & 3.9 & & \\
\hline SE & 0.57 & 1.36 & 1.30 & & & 1.16 & 1.19 & & \\
\hline$N$ & 11 & 11 & 11 & & & 11 & 11 & & \\
\hline Intervention & & & & & & & & & \\
\hline Range & (49 to 57 ) & (51 to 75 ) & (2 to 19$)$ & & & (70 to 80 ) & (15 to 28$)$ & & \\
\hline Mean & 53.2 & 65.9 & 12.7 & 2.58 & $<0.001$ & 75.5 & 22.3 & 7.42 & $<0.001$ \\
\hline SD & 3.0 & 6.3 & 4.9 & & & 3.0 & 3.5 & & \\
\hline SE & 0.90 & 1.90 & 1.48 & & & 0.91 & 1.05 & & \\
\hline$N$ & 11 & 11 & 11 & & & 11 & 11 & & \\
\hline $\begin{array}{l}P \text { (independent } \\
\text { samples } t \text {-test) }\end{array}$ & 0.06 (NS) & 0.012 & $<0.001$ & & & $<0.001$ & $<0.001$ & & \\
\hline
\end{tabular}

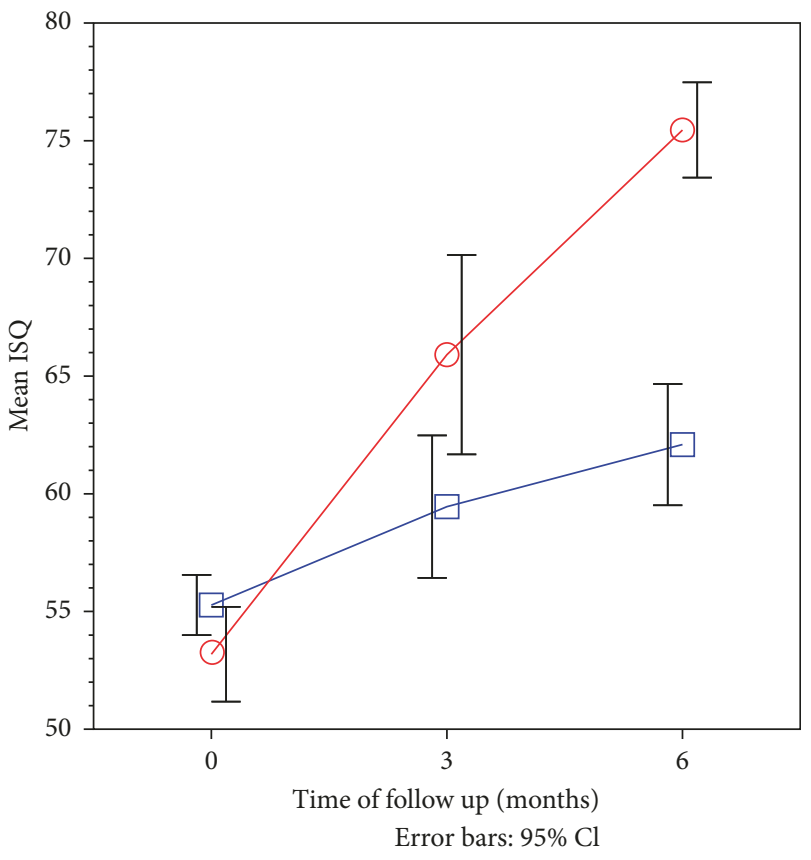

$\begin{array}{ll}\text { Study group } & \\ -\quad \text { Control } & \square \text { Control } \\ - \text { Intervention } & \bigcirc \text { Intervention }\end{array}$

FIGURE 3: Line graph showing the time trend for mean RF values after surgery in the intervention group compared to the control group. values after these two time intervals was used to assess the magnitude of effect in the healing process in each study group. In addition, Cohen's $d$ was used as a standardized measure of effect size to allow fair comparison of effect size between time intervals and between different types of measurements.

As shown in Table 3, after six months of follow-up, the RF values of the control group were significantly increased by a mean of 6.8 units in the control group. This effect was evaluated as a strong effect size (Cohen's $d>0.8$ ). On the other hand, the RF values in the intervention group were significantly increased by a mean of 7.4 units after six months. This also translates to a very strong effect size (Cohen's $d>0.8$ ). Moreover, the effect size after six months compared to immediate postoperative measurements was much stronger for the intervention group (Cohen's $d=7.4$ ) compared to the control group (Cohen's $d=2.25$ ). The extra benefit imposed on the intervention group was significantly higher than that on the control group.

3.3. Fractal Dimension Analysis. The mean FD measured immediately after surgery also showed no important or statistically significant differences between the control and intervention groups (1.338 and 1.319, resp.).

After six months of follow-up, the FD-mesial values were significantly increased by a mean of 0.132 units in the control group and 0.342 units in the intervention group which 
TABLE 4: An intervention-control group comparison in mean change in the FD-mesial side after three and six months of surgery compared to immediate postoperative measurements.

\begin{tabular}{|c|c|c|c|c|c|c|c|c|c|}
\hline & At baseline & $\begin{array}{l}\text { After } 3 \\
\text { months }\end{array}$ & $\begin{array}{l}\text { Changes after } \\
3 \text { months } \\
\text { compared to } \\
\text { immediate }\end{array}$ & $\begin{array}{c}\text { Cohen's } \\
d\end{array}$ & $\begin{array}{c}P \\
\text { (paired } \\
t \text {-test) }\end{array}$ & $\begin{array}{c}\text { After } \\
6 \text { months }\end{array}$ & $\begin{array}{l}\text { Changes after } \\
6 \text { months } \\
\text { composed to } \\
\text { immediate }\end{array}$ & $\begin{array}{c}\text { Cohen's } \\
d\end{array}$ & $\begin{array}{c}P \\
\text { (paired } \\
t \text {-test) }\end{array}$ \\
\hline \multicolumn{10}{|l|}{ Control } \\
\hline Range & $\begin{array}{c}\text { (1.229 to } \\
1.393)\end{array}$ & $\begin{array}{c}\text { (1.293 to } \\
1.498)\end{array}$ & $\begin{array}{c}(0.018 \text { to } \\
0.124)\end{array}$ & & & $\begin{array}{c}\text { (1.377 to } \\
1.568)\end{array}$ & (0.06 to 0.26$)$ & & \\
\hline Mean & 1.319 & 1.376 & 0.056 & 1.13 & $<0.001$ & 1.452 & 0.132 & 2.64 & $<0.001$ \\
\hline $\mathrm{SD}$ & 0.044 & 0.056 & 0.032 & & & 0.052 & 0.059 & & \\
\hline SE & 0.013 & 0.017 & 0.010 & & & 0.016 & 0.018 & & \\
\hline$N$ & 11 & 11 & 11 & & & 11 & 11 & & \\
\hline \multicolumn{10}{|l|}{ Intervention } \\
\hline Range & $\begin{array}{c}\text { (1.213 to } \\
1.393)\end{array}$ & $\begin{array}{l}\text { (1.488 to } \\
1.659)\end{array}$ & $\begin{array}{c}(0.145 \text { to } \\
0.319)\end{array}$ & & & $\begin{array}{l}\text { (1.523 to } \\
1.803)\end{array}$ & $\begin{array}{c}(0.181 \text { to } \\
0.462)\end{array}$ & & \\
\hline Mean & 1.338 & 1.556 & 0.218 & 4.35 & $<0.001$ & 1.680 & 0.342 & 4.88 & $<0.001$ \\
\hline $\mathrm{SD}$ & 0.050 & 0.058 & 0.061 & & & 0.092 & 0.097 & & \\
\hline SE & 0.015 & 0.018 & 0.018 & & & 0.028 & 0.029 & & \\
\hline$N$ & 11 & 11 & 11 & & & 11 & 11 & & \\
\hline$P$ & & & & & & & & & \\
\hline $\begin{array}{l}\text { (independent } \\
\text { samples } t \text {-test) }\end{array}$ & 0.36 (NS) & $<0.001$ & $<0.001$ & & & $<0.001$ & $<0.001$ & & \\
\hline
\end{tabular}

reflects a very strong effect size. Moreover, the effect size after six months compared to immediate postoperative measurements was much stronger for the intervention group (Cohen's $d=4.85$ ) compared to the control group (Cohen's $d=2.64$ ) (Table 4, Figure 4).

Similarly, the FD-distal values were also increased on the distal side of the implant in the intervention group when compared with that of the control group but to a less extent (Table 5, Figure 5).

3.4. Predicting High Implant Stability for FD Measurements. As shown in Figure 6 and Table 6, both FD-mesial and FD-distal sides measurements serve as very good-to-excellent tests with high validity (ROC area exceeding 0.8 ) for predicting high implant stability (ISQ $\geq 70$ ). The mesial side measurements were consistently better than the distal side in this context.

As shown in Table 7, the optimum cutoff value for the FD-mesial side (associated with highest overall accuracy) that predicts a highly stable implant (ISQ $\geq 70$ ) is $\geq 1.505$. At this optimum cutoff value, the mesial side FD value is associated with a perfect sensitivity (100\%) and fairly high specificity (86.5\%). The positive predictive value of a positive test result (predicting a real highly stable implant) was calculated at a pretest probability of $50 \%$ (equal odds for having high stability versus not having based on chance alone), while that of the negative predictive value of the test (excluding the possibility of having high implant stability) was set at $10 \%$ (needing a clinical awareness of high probability of the implant being of low stability).

Having a positive test result for FD-mesial at the optimum cutoff value (FD-mesial measurement of 1.505 or higher) will establish high implant stability with $88.1 \%$ confidence level, while testing negative would exclude high implant stability with $100 \%$ confidence level. The highest

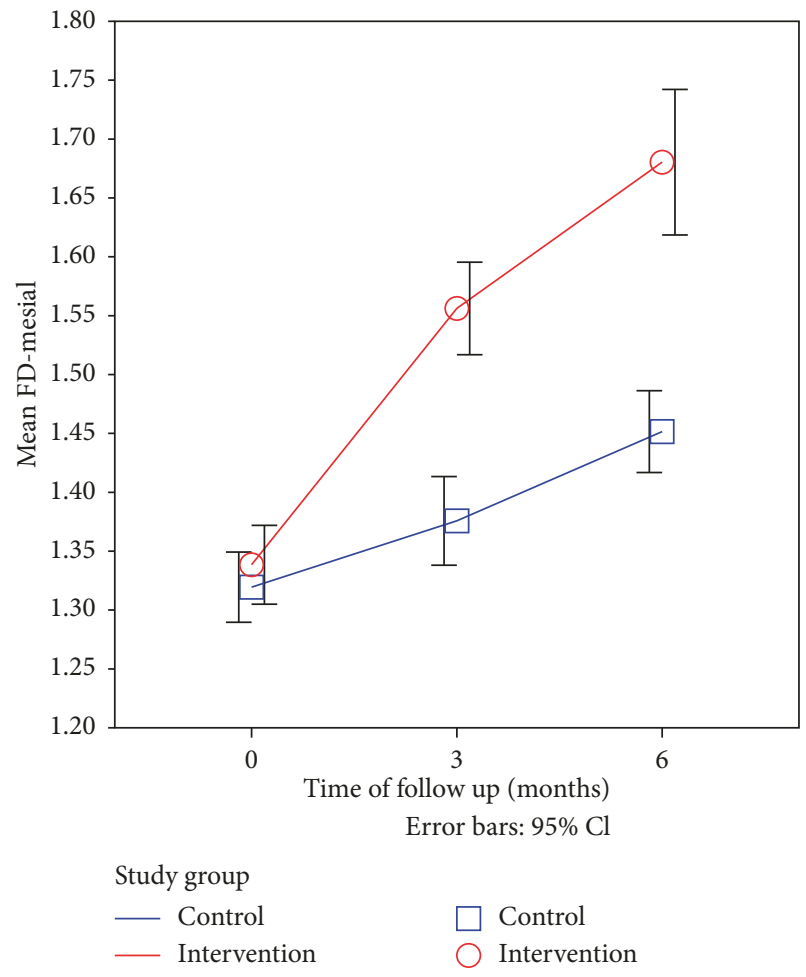

FIGURE 4: Line graph showing the time trend for mean FD-mesial side after surgery in the intervention group compared to the control group.

specificity $(100 \%)$ cutoff value for FD-mesial is $\geq 1.667$. Testing positive at this diagnostic cutoff value (FD-mesial measurement of 1.667 or higher) will establish the diagnosis of high implant stability with $100 \%$ confidence, (Table 5).

As shown in Table 8 and Figure 7, for each one-unit increase in FD-mesial side, the RF value is expected to increase by 
TABLE 5: An intervention-control group comparison in mean change in the FD-distal side after three and six months of surgery compared to immediate postoperative measurements.

\begin{tabular}{|c|c|c|c|c|c|c|c|c|c|}
\hline & At baseline & $\begin{array}{l}\text { After } 3 \\
\text { months }\end{array}$ & $\begin{array}{l}\text { Changes } \\
\text { after } \\
3 \text { months } \\
\text { compared to } \\
\text { immediate }\end{array}$ & $\begin{array}{c}\text { Cohen's } \\
d\end{array}$ & $\begin{array}{c}P \\
\text { (paired } \\
t \text {-test) }\end{array}$ & $\begin{array}{l}\text { After } \\
6 \text { months }\end{array}$ & $\begin{array}{l}\text { Changes after } \\
6 \text { months } \\
\text { compared to } \\
\text { immediate }\end{array}$ & $\begin{array}{c}\text { Cohen's } \\
d\end{array}$ & $\begin{array}{c}P \\
\text { (paired } \\
t \text {-test) }\end{array}$ \\
\hline \multicolumn{10}{|l|}{ Control } \\
\hline Range & $\begin{array}{c}(1.228 \text { to } \\
1.362)\end{array}$ & $\begin{array}{c}\text { (1.312 to } \\
1.398)\end{array}$ & $\begin{array}{c}(0.015 \text { to } \\
0.12)\end{array}$ & & & $\begin{array}{c}(1.363 \text { to } \\
1.49)\end{array}$ & $\begin{array}{c}(0.036 \text { to } \\
0.152)\end{array}$ & & \\
\hline Mean & 1.308 & 1.354 & 0.047 & \multirow[t]{5}{*}{1.55} & \multirow[t]{5}{*}{$<0.001$} & 1.398 & 0.090 & \multirow[t]{5}{*}{2.25} & \multirow[t]{5}{*}{$<0.001$} \\
\hline SD & 0.036 & 0.031 & 0.031 & & & 0.036 & 0.038 & & \\
\hline SE & 0.011 & 0.009 & 0.009 & & & 0.011 & 0.011 & & \\
\hline$N$ & 11 & 11 & 11 & & & 11 & 11 & & \\
\hline Intervention & & & & & & & & & \\
\hline Range & $\begin{array}{c}\text { (1.246 to } \\
1.347)\end{array}$ & $\begin{array}{c}\text { (1.295 to } \\
1.493)\end{array}$ & $\begin{array}{c}(0.008 \text { to } \\
0.15)\end{array}$ & \multirow{5}{*}{1.38} & \multirow{5}{*}{$<0.001$} & (1.32 to 1.68$)$ & $\begin{array}{c}(0.074 \text { to } \\
0.386)\end{array}$ & \multirow{5}{*}{2.68} & \multirow{5}{*}{$<0.001$} \\
\hline Mean & 1.315 & 1.370 & 0.055 & & & 1.503 & 0.188 & & \\
\hline SD & 0.029 & 0.056 & 0.037 & & & 0.095 & 0.087 & & \\
\hline SE & 0.009 & 0.017 & 0.011 & & & 0.029 & 0.026 & & \\
\hline$N$ & 11 & 11 & 11 & & & 11 & 11 & & \\
\hline $\begin{array}{l}P \\
\text { (independent } \\
\text { samples } t \text {-test) }\end{array}$ & 0.61 (NS) & 0.42 (NS) & 0.56 (NS) & & & 0.003 & 0.003 & & \\
\hline
\end{tabular}

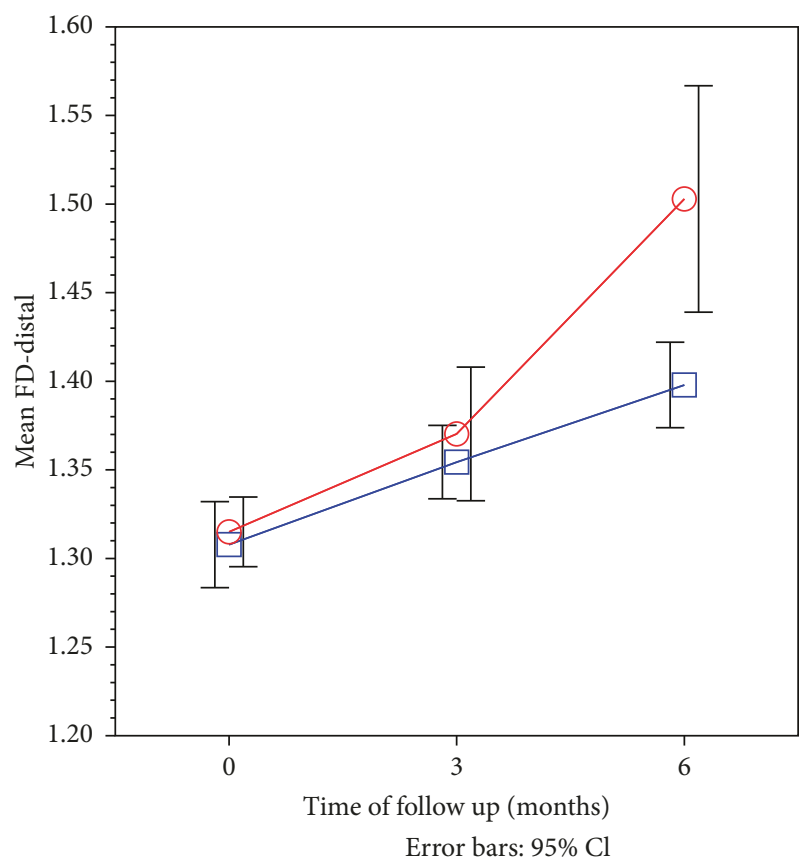

Study group

Control
Intervention

Figure 5: Line graph showing the time trend for mean FD-distal side after surgery in the intervention group compared to the control group.

47.7 units (for each 0.01-unit increase in measured FD, the RF value is expected to increase by around 0.5 ). The model is statistically significant and able to explain $66 \%$ of observed variation in RF values based on FD-mesial measurements. There was a strong and statistically significant linear correlation between RF values and FD-mesial $(r=0.81)$.

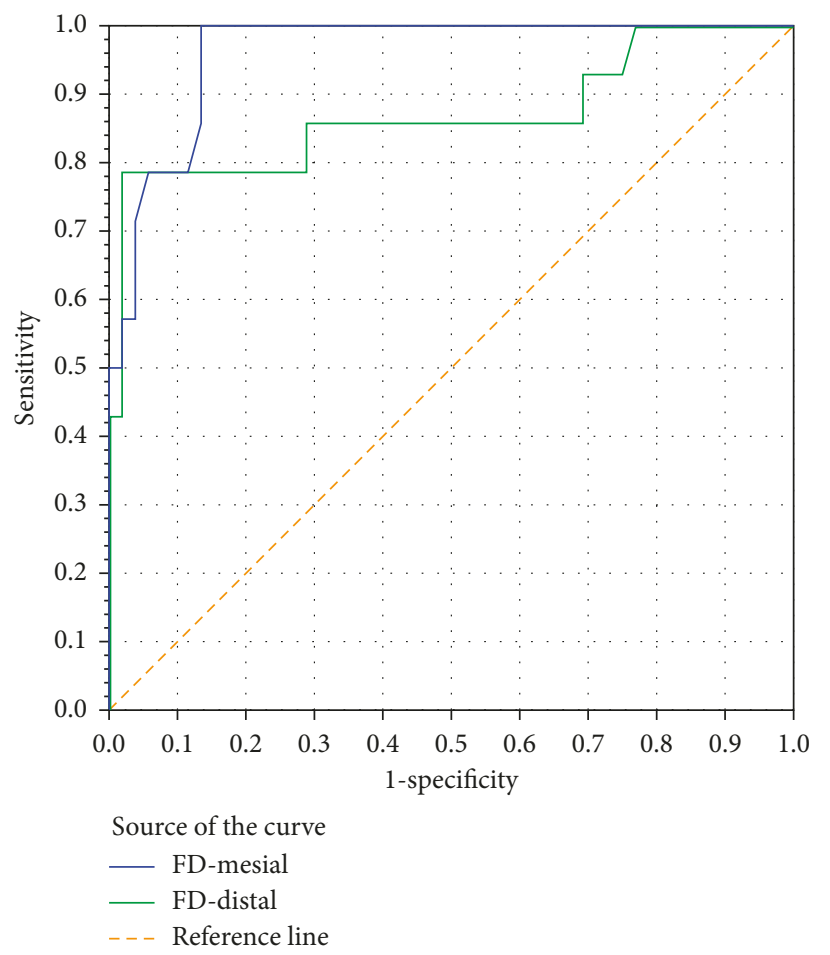

FIGURE 6: ROC curve showing the trade-off between sensitivity (rate of true positive results) and 1-specificity (rate of false positive results) for FD-mesial and FD-distal sides when used as a test to predict high implant stability $(\mathrm{RF} \geq 70)$ in a sample of 66 paired measurements.

TABLE 6: Area under ROC curve for FD-mesial and FD-distal sides when used as a test to predict high implant stability (ISQ $\geq 70$ ).

\begin{tabular}{lcc}
\hline & AUROC & $P$ \\
\hline FD-mesial & 0.962 & $<0.001$ \\
FD-distal & 0.869 & $<0.001$ \\
\hline
\end{tabular}


TABLE 7: Validity parameters for FD-mesial and FD-distal sides when used as a test to predict high implant stability (ISQ $\geq 70$ ).

\begin{tabular}{|c|c|c|c|c|c|}
\hline Positive if $\geq$ cutoff value & $k$ & Specificity & Accuracy & $\begin{array}{c}\text { PPV at pretest } \\
\text { probability }=50 \%\end{array}$ & $\begin{array}{c}\text { NPV at pretest } \\
\text { probability }=10 \%\end{array}$ \\
\hline \multicolumn{6}{|l|}{ FD-mesial } \\
\hline $\begin{array}{l}1.505 \text { (highest sensitivity } \\
\text { and optimum cutoff value) }\end{array}$ & 100.0 & 86.5 & 96.2 & 88.1 & 100.0 \\
\hline 1.516 & 92.9 & 86.5 & 91.1 & 87.3 & 99.1 \\
\hline 1.653 & 50.0 & 98.1 & 63.7 & 96.3 & 94.6 \\
\hline 1.667 (highest specificity) & 50.0 & 100.0 & 64.3 & 100.0 & 94.7 \\
\hline \multicolumn{6}{|l|}{ FD-distal } \\
\hline 1.313 (highest sensitivity) & 100.0 & 23.1 & 78.0 & 56.5 & 100.0 \\
\hline 1.315 & 92.9 & 25.0 & 73.5 & 55.3 & 96.9 \\
\hline 1.419 & 78.6 & 96.2 & 83.6 & 95.3 & 97.6 \\
\hline 1.440 (optimum cutoff value) & 78.6 & 98.1 & 84.1 & 97.6 & 97.6 \\
\hline 1.481 & 42.9 & 98.1 & 58.6 & 95.7 & 93.9 \\
\hline 1.492 (highest specificity) & 42.9 & 100.0 & 59.2 & 100.0 & 94.0 \\
\hline
\end{tabular}

TABle 8: Simple linear regression model for FD-mesial side as a predictor variable and RF values as the dependent (outcome) variable.

\begin{tabular}{lcc}
\hline & Regression coefficient & $P$ \\
\hline (Constant) & -7.5 & $0.24(\mathrm{NS})$ \\
FD-mesial & 47.7 & $<0.001$ \\
\hline
\end{tabular}

$R^{2}=0.66, P($ model $)<0.001, r=0.811$, and $P<0.001$.

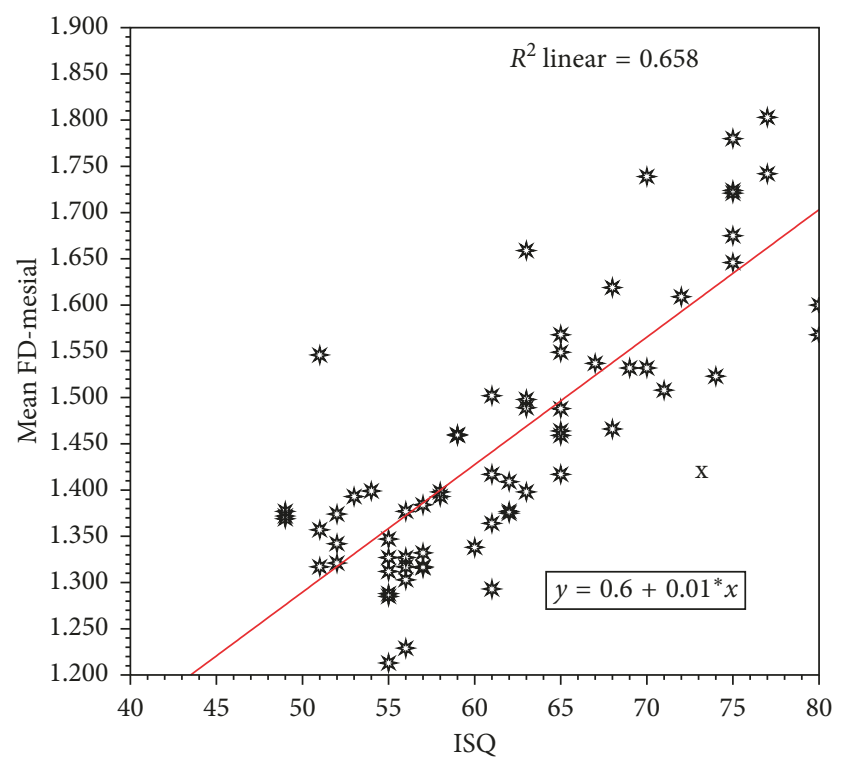

FIGURE 7: Scatter diagram with fitted regression line describing the linear relation correlation between RF- and FD-mesial side.

As seen in Table 9 and Figure 8, for each one-unit increase in the FD-distal side, the RF value is expected to increase by 68.5 units. The model is statistically significant and able to explain $46 \%$ of observed variation in RF values based on FD-distal measurements. There was a statistically significant linear correlation between ISQ and FDdistal $(r=0.678)$, but not as strong as that found in the mesial side.
TABLE 9: Simple linear regression model for the FD-distal side as a predictor variable and RF as the dependent (outcome) variable.

\begin{tabular}{lcc}
\hline & Regression coefficient & $P$ \\
\hline (Constant) & -32.3 & 0.014 \\
FD-distal & 68.5 & $<0.001$ \\
\hline
\end{tabular}

$R^{2}=0.46, P($ Model $)<0.001, r=0.678, P<0.001$.

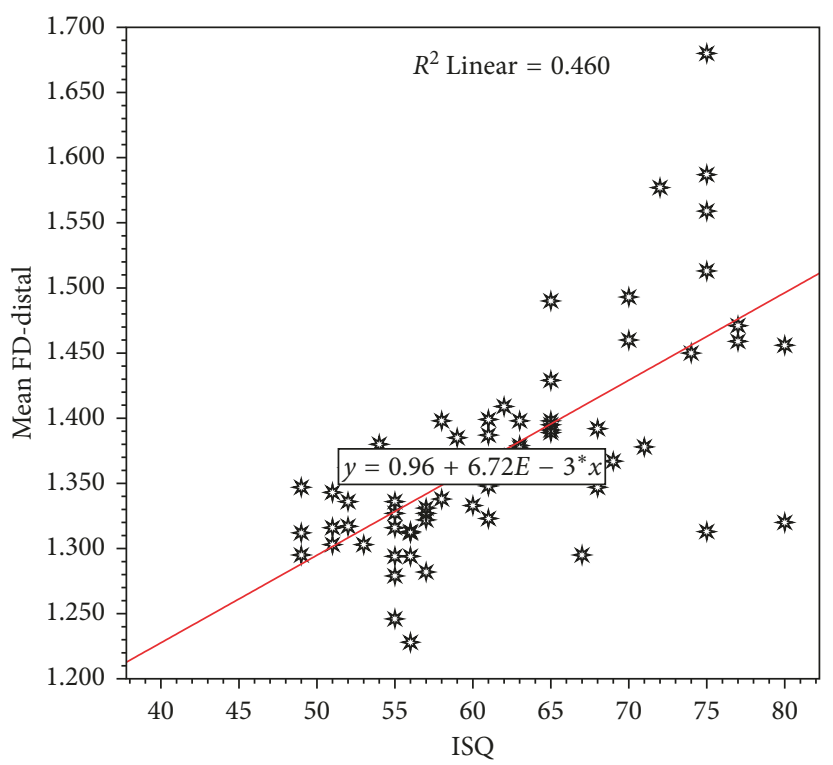

FIGURE 8: Scatter diagram with fitted regression line describing the linear relation correlation between RF- and FD-distal side.

\section{Discussion}

Clinically, the implant stability may be assessed either by recording of periotest value, insertion of torque wrench value, or by the use of the resonance frequency analysis. The RF analysis provides valuable clinical objective data of implant stability. It also detects substantial increase or decrease in stability of the implant, giving a clear ability to measure implant-bone contact and makes clinical comparisons during clinical follow-up. 
In the present study, all the implant fixtures used had the same surface treatment, implant-abutment interface, and thread characteristics. Regarding the ISQ values obtained from the $\mathrm{RF}$ analysis, the effect size after six months was much stronger for the LIPUS-treated intervention group (Cohen's $d=7.4$ ) the compared to the control group (Cohen's $d=2.25$ ). These findings were in agreement with that of Nedir et al. [25]. However, scarce evidence has been provided so far on Osstell ISQ's reliability [26]. The RF method is influenced by some factors including implant length, implant diameter, implant geometry, implant surface characteristic, and placement position, as well as bone quality and bone quantity [27]. Implant stability quotient (ISQ) is a scale developed by Osstell for implant stability. It converts the resonance frequency values ranging from 3,500 to $8,500 \mathrm{~Hz}$ into an ISQ of 0 to 100. A high value indicates greater stability, while a low value indicates instability. Values greater than 65 are recommended as successful implant stability. Even though Osstell is clinically used, there are not much convincing data on the relation between boneimplant interface and ISQ values [28, 29]. RF devices still have some uncertainties because of the observer subjectivity. There has been a search for quantitative methods to control the subjectivity variation in interpretation.

The reliability of fractal dimension calculations from the radiographs was assessed in several studies [15, 30]. Calculation of FD has become a popular method to characterize image textures. In dental radiology, FD calculation can be used to quantify trabecular bone structure for detection of bone changes associated with periodontitis [17], periapical pathology [15], systemic diseases [24, 31], and dental implants $[19,32]$. We used standardized digital intraoral radiographs to assess the FD on two implant's protocols. Tolga et al. [32] suggested that fractal analysis could be a useful method for understanding the healing process around implants and implant stability quotient. Onem et al. [33] measured the FD around implants using the box-counting method from the digital panoramic images, and they found that FD values of implant-bearing bone following initial healing was lower than the FD values in the alveolar bone surrounding the contralateral premolar teeth, but the difference was not significant. In the present study, the fractal dimension after 6 months of implant placement had increased significantly $(P<0.01)$ in both groups, suggesting an increase in the amount of bony microstructure around the implant [20]. This increase suggests complete bone healing around implants. Veltri et al. [19] used animal models to investigate the correlations between FA results and insertion torque and RF. A significant correlation was found with final insertion torques, but not with resonance frequencies. Their results also defined a value of 1.83 as the break point of soft bone quality. Veltri et al. [34] measured FD from mesial and distal aspects of implants using the box-counting method on intraoral radiographs, and the mean reported was 1.47 which is close to what was reported in the present study after 6 months of implant placement (1.39-1.45). Lee et al. [18] observed a strong relationship between primary implant stability and FD using digitized panoramic films and the tilecounting method.
In the present study, there was a statistically significant linear correlation between the ISQ values from the RF and the FD values on both sides of the implant with the mesial side of the intervention group being higher than that on the distal side. This could be due to the large surface area of the LIPUS device used in the present study which provides stronger stimulation on the site closer to the probe (the mesial site of the implant); therefore, denser bone formation was expected on this site on a long run. Nevertheless, the FD values on the mesial and distal sides of the implant remains as very good-to-excellent tests with high validity (ROC area exceeding 0.8) for predicting high implant stability (ISQ $>70 \%$ ). Our results were in agreement with that of Ilhan et al. [35] Lee et al. [18] also suggested that the FD acquired from panoramic radiographs may be a useful predictor of the initial dental implants stability. Therefore, the use of the FD method as a cost-effective one to assess trabecular bone changes around dental implants during follow-up periods is one of the recommendations of this study. No previous studies have been conducted to calculate the optimum cutoff value of FD to predict high implant stability (ISQ $>70 \%$ ). Using the area under the ROC curve, showed that the optimum cutoff FD value of 1.667 from the mesial side of the implant will establish high implant stability with $100 \%$ confidence. Furthermore, for every one-unit increase in the FD-mesial side, the ISQ value from the RF is expected to increase by 47.7 units. Because no other studies have predicted the implant stability from combining the qualitative and quantitative bone at boneimplant interface from digital intraoral radiographs, it is not possible to compare these results with other studies. Onem et al. [33] have used digital panoramic radiographs to quantify the structural changes of mandibular alveolar bone around the dental implants during initial healing. They found that satisfactory bone healing after the implant placement may be monitored by calculating the FD. Lee et al. [18] suggested a unified method to calculate the FD, like proper selection of the area and the size of ROI, methods of FD counting (tile-or box-counting methods), and the type of radiographic image used for the analysis. Although these results may be regarded as preliminary, both ISQ from RF and FD may be reliably recommended for quantitative evaluation of primary and secondary implant stability using digital intraoral radiographic images throughout implant healing and loading periods. Application of the standardized procedures and comparison of the results of these methods with other measures define the bone quality like DEXA, and the value of FD would be more precisely assessed.

\section{Conclusion}

The fractal dimension analysis as a noninvasive cost-effective method could be helpful in assessing bone trabecular patterns around the implants in different clinical situations. Intraoral digital radiographs could be used to monitor the healing process around the implants. Although these results may be regarded as preliminary, implants with low FD values may indicate a decrease in stability, and this should 
alert the practitioner to pay more attention through more rigorous follow-up schedules and take further precautions.

\section{Conflicts of Interest}

The authors declare that they have no conflicts of interest.

\section{References}

[1] M. Hof, B. Pommer, N. Zukic, C. Vasak, M. Lorenzoni, and W. Zechner, "Influence of prosthetic parameters on periimplant bone resorption in the first year of loading: a multi-factorial analysis," Clinical Implant Dentistry and Related Research, vol. 17, no. 1, pp. e183-e191, 2015.

[2] X. Q. Gu, Y. M. Li, J. Guo, L. H. Zhang, D. Li, and X. D. Gai, "Effect of low intensity pulsed ultrasound on repairing the periodontal bone of Beagle canines," Asian Pacific Journal of Tropical Medicine, vol. 7, no. 4, pp. 325-328, 2014.

[3] R. Shiraishi, C. Masaki, A. Toshinaga et al., "The effects of lowintensity pulsed ultrasound exposure on gingival cells," Journal of Periodontology, vol. 82, no. 10, pp. 1498-1503, 2011.

[4] S. H. Kim and K. S. Hong, "Histologic evaluation of lowintensity pulsed ultrasound effects on bone regeneration in sinus lift," Journal of Periodontal \& Implant Science, vol. 40, no. 6, pp. 271-275, 2010.

[5] S. K. Hsu, W. T. Huang, B. S. Liu, S. M. Li, H. T. Chen, and C.-J. Chang, "Effects of near-field ultrasound stimulation on new bone formation and osseointegration of dental titanium implants in vitro and in vivo," Ultrasound in Medicine \& Biology, vol. 37, no. 3, pp. 403-416, 2011.

[6] O. Bissinger, F. A. Probst, K. D. Wolf, A. Jeschke, J. Weitz, and A. Kolk, "Comparative 3D micro-CT and 2D histomorphometry analysis of dental implant osseointegration in the maxilla of minipigs," Journal of Clinical Periodontology, vol. 44, no. 4, pp. 418-427, 2017.

[7] K. Horner, K. Karayianni, A. Mitsea et al., "The mandibular cortex on radiographs as a tool for osteoporosis risk assessment: the OSTEODENT Project," Journal of Clinical Densitometry, vol. 10, no. 2, pp. 138-146, 2007.

[8] W. G. Geraets, P. F. Van der Stelt, C. J. Netelenbos, and P. J. Elders, "A new method for automatic recognition of the radiographic trabecular pattern," Journal of Bone and Mineral Research, vol. 5, no. 3, pp. 227-233, 1990.

[9] B. Cortet, P. Dubois, N. Boutry, P. Bourel, A. Cotton, and $\mathrm{X}$. Marchandise, "Image analysis of the distal radius trabecular network using computed tomography," Osteoporosis International, vol. 9, no. 5, pp. 410-419, 1999.

[10] N. L. Fazzalari and I. H. Parkinson, "Fractal properties of cancellous bone of the iliac crest in vertebral crush fracture," Bone, vol. 23, no. 1, pp. 53-57, 1998.

[11] E. Oczeretko, M. Borowska, I. Szarmach, A. Kitlas, J. Szarmach, and A. Radwański, "Fractal analysis of dental radiographic images in the irregular regions of interest," Advances in Intelligent and Soft Computing, vol. 69, pp. 191-199, 2010.

[12] G. M. Tosoni, A. G. Lurie, A. E. Cowan, and J. A. Burleson, "Pixel intensity and fractal analyses: detecting osteoporosis in perimenopausal and postmenopausal women by using digital panoramic images," Oral Surgery, Oral Medicine, Oral Pathology, Oral Radiology, and Endodontology, vol. 102, no. 2, pp. 235-241, 2006.

[13] O. Zmeskal, M. Vesely, M. Nezadal, and M. Buchnicek, "Fractal analysis of image structures," Harmonic and Fractal Image Analysis, pp. 3-5, 2001.
[14] I. Sánchez and G. Uzcátegui, "Fractals in dentistry,” Journal of Dentistry, vol. 39, no. 4, pp. 273-292, 2011.

[15] Y. Y. Yu, H. Chen, C. H. Lin et al., "Fractal dimension analysis of periapical reactive bone in response to root canal treatment," Oral Surgery, Oral Medicine, Oral Pathology, Oral Radiology, and Endodontology, vol. 107, no. 2, pp. 283-288, 2009.

[16] M. K. Shrout, B. Roberson, B. J. Potter, J. M. Mailhot, and C. F. Hildebolt, "A comparison of 2 patient populations using fractal analysis," Journal of Periodontology, vol. 69, no. 1, pp. 9-13, 1998.

[17] S. X. Updike and H. Nowzari, "Fractal analysis of dental radiographs to detect periodontitis-induced trabecular changes," Journal of Periodontal Research, vol. 43, no. 6, pp. 658-664, 2008.

[18] D. H. Lee, Y. Ku, I. C. Rhyu et al., “A clinical study of alveolar bone quality using the fractal dimension and the implant stability quotient," Journal of Periodontal \& Implant Science, vol. 40, no. 1, pp. 19-24, 2010.

[19] M. Veltri, M. Ferrari, and P. Balleri, "Correlation of radiographic fractal analysis with implant insertion torque in a rabbit trabecular bone model," International Journal of Oral \& Maxillofacial Implants, vol. 26, no. 1, pp. 108-114, 2011.

[20] L. Jolley, S. Majumdar, and S. Kapila, "Technical factors in fractal analysis of periapical radiographs," Dentomaxillofacial Radiology, vol. 35, no. 6, pp. 393-397, 2006.

[21] E. N. Kerr, B. L. Mealey, M. E. Noujeim, D. J. Lasho, P. V. Nummikoski, and J. T. Mellonig, "The effect of ultrasound on bone dimensional changes following extraction: a pilot study," Journal of Periodontology, vol. 79, no. 2, pp. 283-290, 2008.

[22] K. Isoda, Y. Auykawa, Y. Tsukiyama, M. Sogo, Y. Matsushita, and K. Koyano, "Relationship between the bone density estimated by cone-beam computed tomography and the primary stability of dental implants," Clinical Oral Implants Research, vol. 23, no. 7, pp. 832-836, 2012.

[23] S. C. White and D. J. Rudolph, "Alterations of the trabecular pattern of the jaws in patients with osteoporosis," Oral Surgery, Oral Medicine, Oral Pathology, Oral Radiology, and Endodontology, vol. 88, no. 5, pp. 628-635, 1999.

[24] A. K. Demirbas, S. Ergun, P. Guneri, B. O. Aktener, and H. Boyacioglu, "Mandibular bone changes in sickle cell anemia: fractal analysis," Oral Surgery, Oral Medicine, Oral Pathology, Oral Radiology, and Endodontology, vol. 106, no. 1, pp. e41-e48, 2008.

[25] R. Nedir, M. Bischof, S. Szmukler-Moncler, J. P. Bernard, and J. Samson, "Predicting osseointegration by means of implant primary stability: a resonance frequency analysis study with delayed and immediately loaded ITI SLA implants," Clinical Oral Implants Research, vol. 15, no. 5, pp. 520-528, 2004.

[26] M. Herrero-Cliomate, R. Santos-Garcia, R. Jaramillo-Santos et al., "Assessment of Osstell ISQ's reliability for implant stability measurement: a cross-sectional clinical study," Medicina Oral Patología Oral y Cirugia Bucal, vol. 18, no. 6, pp. e877-e882, 2013.

[27] A. H. Muhamed, C. Georges, M. Mustafa, and A. Abdulgani, "Implant stability: methods and recent advances," IOSR Journal of Dental and Medical Sciences, vol. 16, no. 8, pp. 13-23, 2017.

[28] N. Meredith, "Assessment of implant stability as a prognostic determinant," International Journal of Prosthodontics, vol. 11, pp. 491-501, 1998.

[29] H. M. Huang, C. L. Chiu, C. Y. Yeh, C. T. Lin, L. H. Lin, and S. Y. Lee, "Early detection of implant healing process using 
resonance frequency analysis," Clinical Oral Implants Research, vol. 14, no. 4, pp. 437-443, 2003.

[30] T. E. Southard and K. A. Southard, "Detection of simulated osteoporosis in maxilla using radiographic texture analysis," IEEE Transactions on Biomedical Engineering, vol. 43, no. 2, pp. 123-132, 1996.

[31] U. E. Ruttimann, R. L. Webber, and J. B. Hazelrig, "Fractal dimension from radiographs of periodontal alveolar bone: a possible diagnostic indicator of osteoporosis," Oral Surgery, Oral Medicine, Oral Pathology, vol. 74, no. 1, pp. 98-110, 1992.

[32] T. Tolga, D. Erhan, and U. Serdar, "Radiographic fractal and clinical resonance frequency analyses of posterior mandibular dental implants: their possible association with mandibular cortical index with 12-month follow up," Implant Dentistry, vol. 25, no. 6, pp. 789-795, 2016.

[33] E. Onem, B. G. Baksi, and E. Sogur, "Changes in the fractal dimension, ferret diameter, and lacunarity of mandibular alveolar bone during initial healing of dental implants," International Journal of Oral \& Maxillofacial Implants, vol. 27, no. 5, pp. 10089-10113, 2012.

[34] M. Veltri, P. Balleri, and M. Ferrari, "Damping factor for monitoring the bone interface at dental implants," Clinical Oral Implants Research, vol. 18, no. 6, pp. 738-742, 2007.

[35] B. Ilhan, P. Guneri, A. Saracoglu, H. Koca, and H. Boyacioglu, "A comparison of fractal dimension values of peri-implant bone and healthy contralateral side using panoramic radiographs," Journal of Oral and Maxillofacial Radiology, vol. 3, no. 1, pp. 1-6, 2015. 


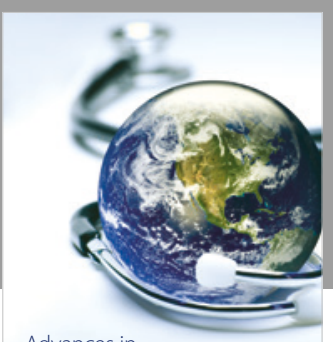

Advances in
Public Health

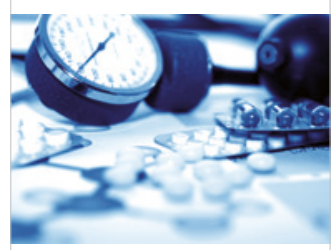

Case Reports in

Medicine

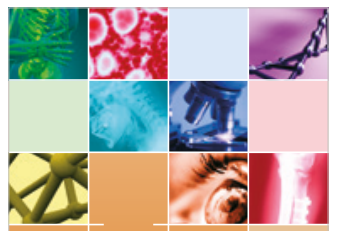

niernational Journal of

Biomaterials
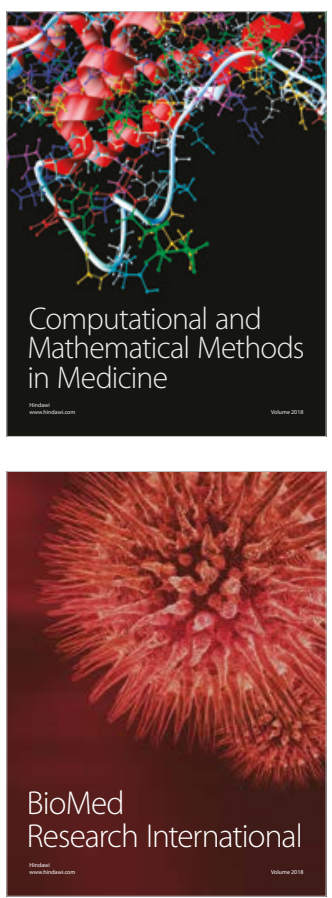

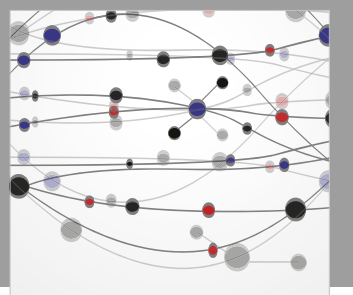

The Scientific World Journal Dentistry

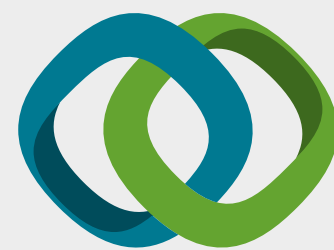

Hindawi

Submit your manuscripts at

www.hindawi.com
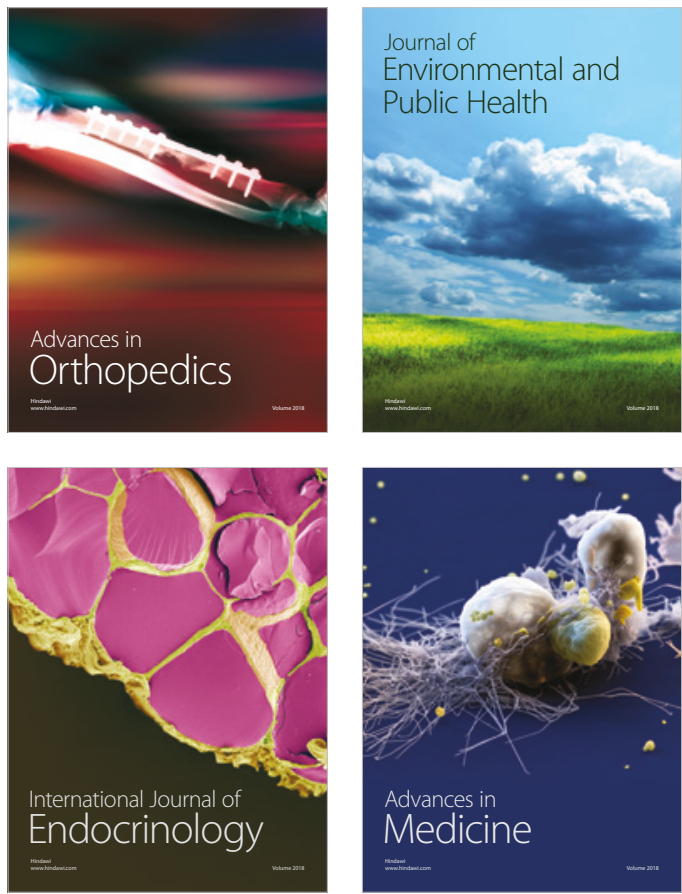
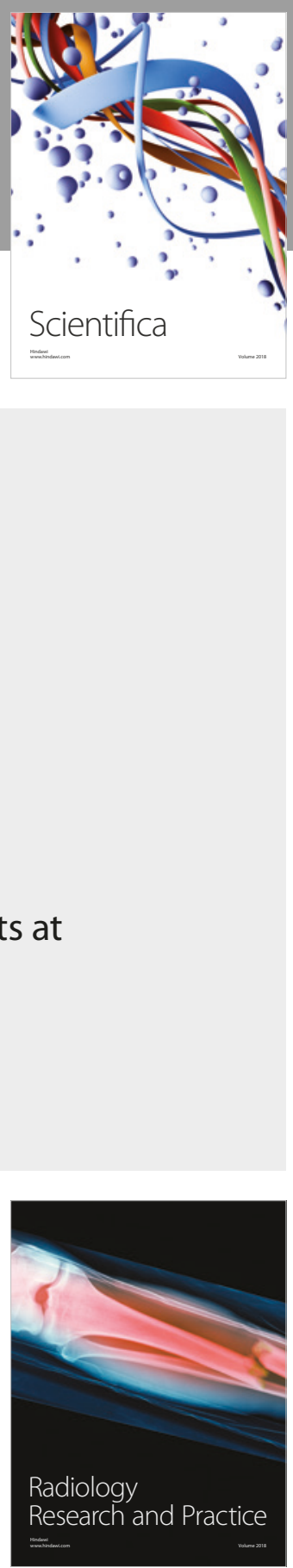

Scientifica

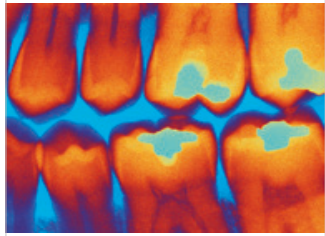

Case Reports in

Dentistry
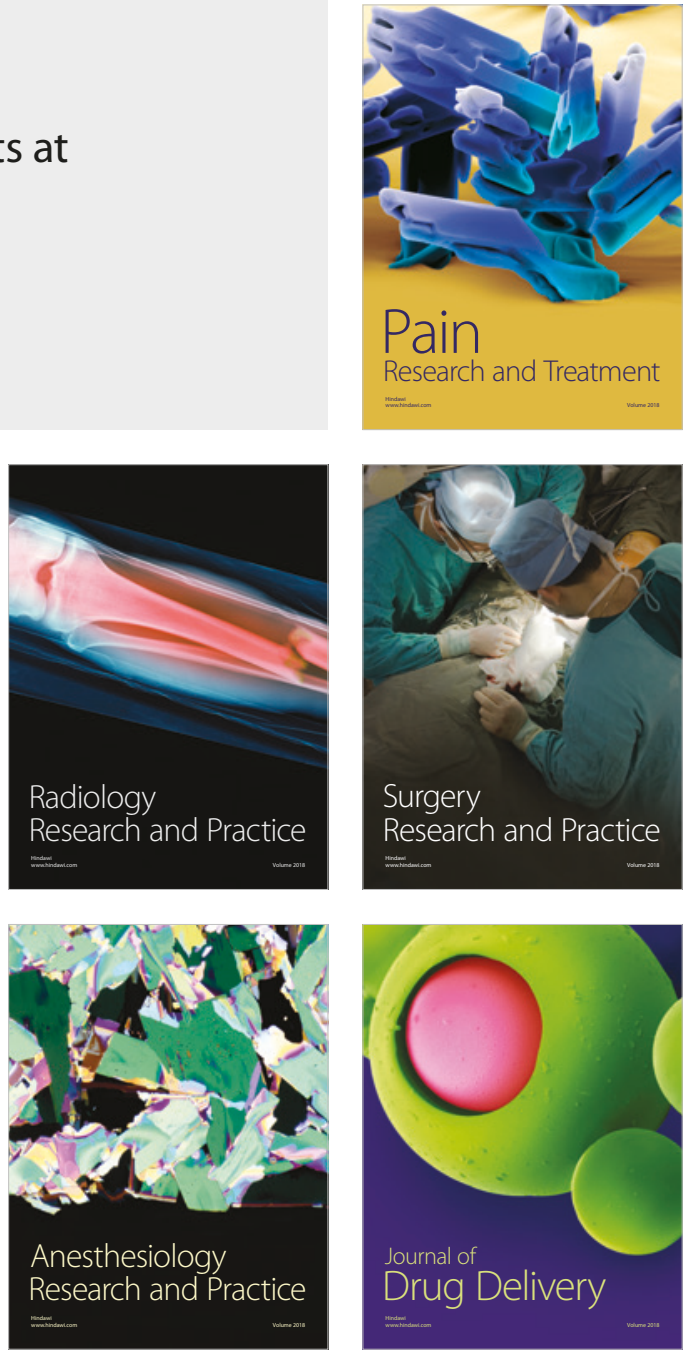